Article

\title{
Hierarchical Structured Polyimide-Silica Hybrid Nano/Microfiber Filters Welded by Solvent Vapor for Air Filtration
}

\author{
Dawei Li ${ }^{\dagger}$, Ying Shen ${ }^{\dagger}$, Lanlan Wang, Feng Liu, Bingyao Deng * ${ }^{(\mathbb{C}}$ and Qingsheng Liu \\ Key Laboratory of Eco-Textiles (Ministry of Education), Nonwoven Technology Laboratory, Jiangnan University, \\ Wuxi 214122, China; ldw@jiangnan.edu.cn (D.L.); shenying1@sina.cn (Y.S.); 15852776701@163.com (L.W.); \\ fengliu_windy@163.com (F.L.); qsliu@jiangnan.edu.cn (Q.L.) \\ * Correspondence: bydeng@jiangnan.edu.cn; Tel.: +86-13806185561 \\ + These authors contributed equally to this work.
}

Received: 22 September 2020; Accepted: 22 October 2020; Published: 27 October 2020

\begin{abstract}
Electrospun polymer membranes were considered to be promising materials for fine particulate matter (PM) filtration. However, the poor mechanical properties of the electrospun membrane restricted their application for pressure-driven air filtration. Herein, strength-enhanced electrospun polyimide (PI) membranes were demonstrated via a synergistic approach. Solvent-vapor treatment was utilized to introduce extra bonding at the cross points of $\mathrm{PI}$ nanofiber, while $\mathrm{SiO}_{2}$ nanoparticles $\left(\mathrm{SiO}_{2} \mathrm{NPs}\right)$ were used to reinforce the body of nanofibers. The mechanical strength and filtration performance of hybrid membranes could be regulated by adjusting the quantity of $\mathrm{SiO}_{2} \mathrm{NPs}$. The tensile strength of the pure PI membrane was increased by $33 \%$ via adding $1.5 \% \mathrm{SiO}_{2} \mathrm{NPs}$, which was further promoted by $70 \%$ after solvent-vapor treatment. With a slight reduction in pressure drop $(6.5 \%)$, the filtration efficiency was not greatly suppressed by welding the $\mathrm{SiO}_{2} \mathrm{NP}$ hybrid PI nanofibers. Moreover, the welded composite filter showed high particulate $(0.3-1.0 \mu \mathrm{m}$ ) filtration efficiency (up to nearly $100 \%$ ) and stable pressure drop throughout the 20 tested filtration cycles.
\end{abstract}

Keywords: electrospinning; hierarchical structure; hybrid nano/microfiber filters; air filtration

\section{Introduction}

With economic and industrial development, pollutants and their impact on human health have become a priority in recent research. The fine particulate matters (PM) are the primary abundant pollutant in the air, characterized by their small profile and their high specific area. These features allow them to be easily inhaled and passed into the bronchi and lungs through the respiratory tract and cause serious health problems [1]. Several studies have linked long-term exposure to PM to a variety of diseases, including strokes, lung disease, cardiovascular disease, and even cancer [2-4]. Therefore, effectively removing PM from polluted air is an urgent issue.

The porous membrane-type filter and fibrous membrane-type filter are the predominant, widely used conventional air filter until now [5-9]. The porous one made of the solid substrate has interconnected pores in the membrane, which can block the particles, while gas passes through the pores. However, the porosity of these filters is quite low $(<30 \%)$, which means that high filtration efficiency is always accompanied by high filtration resistance. The fibrous membrane-type filters consisting of well-aligned or randomly arranged fibers form a reticular support structure and tortuous pore channels, making it attractive in various fields, which turned out to be a feasible and promising method to fight against air pollution. The porous structure and open pores allow the easy passage of air molecules, which will also block the particulate matters with higher capacity. Until now, various methods have been invented to prepare high-performance air filter materials, including melt-blowing [10-12], spun-bonding [13,14], 
and needle-punching $[15,16]$. These fibrous structures consisting of fibers of micro-scale could block the particles in the air through thick physical barriers along with adhesion. Nevertheless, the fiber-based filters prepared via these methods are suffering from high air resistance due to the direct strike of air molecules against the fibers and densely compacted structure of fiber assembly. Electret materials are also applied in the air filtration, as they can attract PM due to fortissimo electrostatic force. However, the low initial pressure drop is accompanied by safety hazards and a short service life $[12,17,18]$.

The nanofiber, however, is known for its large surface area and high surface energies compared to the micrometer-sized fiber; consequently, the interactions with PM and the filtration efficiencies are impressively enhanced $[19,20]$. Moreover, around the periphery of fibers, the aerodynamic behavior of airflow was proved to be changed significantly when the size of fibers reduces to the nanoscale [21-23], which is called the "slip flow phenomenon". It was believed that the single fiber would not cause any turbulence as the airflow passed by when the fiber diameter was close to $65 \mathrm{~nm}$. Therefore, a significant reduction in drag force of the airstream could be achieved [21,24]. Electrospinning is found to be effective in capturing fine particles relying on their ultralow diameters, tunable porous structure, and high specific area $[19,25,26]$. Nevertheless, due to the dense packing of nanofibers (with a limited porosity of $<90 \%$ ), electrospinning nanofiber membranes (ENMs) tend to raise the pressure drop significantly.

In previous reports, the pressure drop is positively correlated with the solid volume fraction of the filter when this filter has a fixed diameter and thickness [21]. For an outstanding functionalization of filter membranes, hierarchical structures, especially the roughness in nanoscale on the surface of electrospun nanofibers, are exceptionally critical [27-29]. The formation of protuberance on the surface of nanofibers could significantly improve the surface roughness as well as increasing the effective surface area, leading to the increased project area of the nanofiber at the inlet. Therefore, it is hypothesized that the filtration performance of the membranes will be further improved by introducing nanoparticles on the surface of electrospun nanofibers. On the other hand, inorganic electrets could promote charge trapping, which could enhance the filtration properties [17]. Silica nanoparticles $\left(\mathrm{SiO}_{2} \mathrm{NPs}\right)$ electrets are considered as promising alternatives for novel fibrous materials conception for air filtration, due to their outstanding electret behavior stems from the dipole orientation and the charge storage [30,31].

Although electrospun mats of hybrid polymer nanofibers could meet most of the demands in terms of filtering performance, the weak mechanical strength limits their further application. Thus, strength enhancement of electrospun filters is particularly critical, which can be typically classified into three main strategies: twisting electrospun nanofibers into yarns [32,33], reinforcing fibers by incorporating extra materials [34], and welding fibers with more contact points [35-37]. Changing the nonwoven mats into twisted nanofiber yarns could improve the tensile strength along the axis of yarn; however, the resulted fabric would suffer from reduced porosity and less anisotropy, which is less suitable in the application of filtration. Adding inorganic nanoparticles is another typical reinforcement method to boost the mechanical strength of ENMs. Other strategies, including heating and photo and chemical cross-linking at their cross points, were utilized to strengthen the ENMs. Regardless of the enhancement in mechanical properties, these methods are too complex to operate and typically lead to dimensional shrinkage caused by the relaxation of molecule chains in the amorphous region [38,39]. Whereas, a systematic study of the synergistic effect of inorganic particles reinforcement and extra welding on mechanical and air filtration performance of ENMs has not yet been reported.

In this contribution, electrospun polyimide (PI) nanofibers were selected as building blocks for their brilliant thermal and physicochemical stability as well as their high mechanical strength $[40,41]$. Firstly, hierarchically structured $\mathrm{SiO}_{2} \mathrm{NPs}$ hybrid $\mathrm{PI}\left(\mathrm{SiO}_{2} @ \mathrm{PI}\right)$ fibrous filters with robust filtration performances were fabricated with the incorporation of $\mathrm{SiO}_{2} \mathrm{NPs}$ through electrospinning. Subsequently, inter-fiber bonding was generated by positioning the as-spun nanofiber in the fume of solvents, which could further improve the mechanical strength. Notably, PI nanofibers were reinforced using as-received $\mathrm{SiO}_{2} \mathrm{NPs}$ without modification. On the other hand, solvent-vapor treatment was easily conducted with negligible shrinkage caused in the dimension. Benefitting from this unique inorganic-organic 
composite structure, a new filter with enhanced mechanical strength and promoted high filtration efficiency with recyclability could be prepared.

\section{Experiments}

\subsection{Materials}

Copolyimide staple fibers (brand name: P84), which belong to micro denier-fibers, was supplied by Evonik (Althofen, Austria). Hydrophilic $\mathrm{SiO}_{2} \mathrm{NPs}$ with a mean particle size of $12 \mathrm{~nm}$ were purchased from King Chemical (Shanghai, China). N, N-Dimethylacetamide (DMAc) and N, N-dimethylformamide (DMF) were obtained from Sinopharm Chemical Reagent (Shanghai, China). All the chemicals were used as received.

\subsection{Methods}

\subsubsection{Preparation of $\mathrm{SiO}_{2} @ P I$ Hybrid Membranes}

P84 staple fibers purchased from Evonik were pretreated and rinsed with acetone and ethanol to remove impurities, followed by drying under vacuum at $60^{\circ} \mathrm{C}$ for $2 \mathrm{~h}$. PI solution was prepared by dissolving $1 \mathrm{~g}$ P84 stable fibers in $10 \mathrm{~mL}$ DMAc, then magnetic stirring for $2 \mathrm{~h}$ at $80{ }^{\circ} \mathrm{C}$ to obtain a homogenous PI solution $10 \%(w / v)$. $\mathrm{SiO}_{2} @$ PI solution was further generated by adding $\mathrm{SiO}_{2} \mathrm{NPs}_{\text {into }}$ the PI solution with the ratios of 1.0, 1.5, 2.0, 3.0, 4.0\% by weight to PI, respectively. To generate uniform dispersion, the PI solution was stirred at $300 \mathrm{rpm}$ for $2 \mathrm{~h}$ at $80^{\circ} \mathrm{C}$, followed by ultrasonic treating for $1 \mathrm{~h}$. The $\mathrm{SiO}_{2} @ P I$ nanofiber membranes were manufactured on the electrospinning apparatus under the process condition of a high voltage of $25 \mathrm{kV}$, collecting distance of $20 \mathrm{~cm}$, and feeding rate of $1 \mathrm{~mL} / \mathrm{h}$. All experiments were carried out at room temperature and 50-60\% room humidity.

\subsubsection{Preparation of PPS-SiO $\mathrm{S}_{2} @ \mathrm{PI}$ Composite Filters}

To test the filtration performance, the $\mathrm{SiO}_{2} @ \mathrm{PI}$ hybrid nanofiber membrane was firstly deposited on the support layer of polyphenylene sulfide (PPS) needle-punched nonwoven, which was fixed on the rotating drum $(80 \mathrm{rpm} / \mathrm{min})$. Afterward, the composite filter was cut into a circle with a diameter of about $15 \mathrm{~cm}$ and placed in a closed vial with DMF vapor (generated from DMF solution) at $40{ }^{\circ} \mathrm{C}$ for $0.5 \mathrm{~h}$. Thus, extra bonding would be generated between the PPS nonwoven and PI electrospun nanofiber membrane by partially dissolving PI nanofiber in the fume of DMF vapor. The composite filter with bonded hybrid nanofibers was dried at ambient temperature for $12 \mathrm{~h}$ to allow the evaporation of the residual solvent.

\subsection{Characterizations}

The surface and cross-sectional morphologies of $\mathrm{SiO}_{2} @ P I$ hybrid nanofiber were determined via the scanning electron microscope (SEM, Japan). The diameter of fibers was measured in the SEM images with the help of image processing software ImageJ. The chemical composition of $\mathrm{SiO}_{2} @ \mathrm{PI}$ hybrid nanofiber was analyzed by Fourier transform infrared (FTIR) spectroscopy (Thermo Fisher Scientific, Waltham, MA, USA) in the range of $400-4000 \mathrm{~cm}^{-1}$. X-ray diffraction (XRD) spectra were recorded on an X-ray diffractometer (Bruker AXS GmbH, Germany) with $\mathrm{Cu}$ X-ray source and a scanning range from 5 to $45^{\circ}$. The pore size of samples was tested on capillary flow porometry (CFP-1100A, Skei, Ithaca, NY, USA). Water contact angles (WCA) $(10 \mu \mathrm{L})$ were calculated using a contact angle goniometer (Rame Hart, Succasunna, NJ, USA) equipped with an HD camera.

The thermal shrinkage behavior of the $\mathrm{SiO}_{2} @ \mathrm{PI}$ hybrid membranes was tested by calculating the specific value of the area before and after annealing at $220^{\circ} \mathrm{C}$ for $1 \mathrm{~h}$. Thermogravimetric (TG) analysis was scanned from 50 to $800{ }^{\circ} \mathrm{C}$ at a heating rate of $10{ }^{\circ} \mathrm{C} / \mathrm{min}$ under $\mathrm{N}_{2}$ atmosphere using a Q500 (TA Instrument Company, Milford, MA, USA). Differential scanning calorimeter (DSC) measurement 
was carried out from 30 to $400{ }^{\circ} \mathrm{C}$ with a heating rate of $10{ }^{\circ} \mathrm{C} /$ min under $\mathrm{N}_{2}$ atmosphere (Q200, TA Instrument Company, Milford, MA, USA).

The tensile test was performed on the Shimadzu testing system (EZ-S, Shanghai Bahens Instrument Co., China). Rectangular samples with a length of $50 \mathrm{~mm}$ and a width of $10 \mathrm{~mm}$ were tested at a strain rate of $3 \mathrm{~mm} / \mathrm{min}$.

The filtration efficiency, the pressure drop, and the air permeability of the membranes were tested as described previously [42], using an automated filter tester (LZC-H, Suzhou Hua Da Instrument and Equipment Co., China). The experimental set-up (automated filter tester, Suzhou Hua Da Instrument and Equipment Co., China) is shown in Figure 1. The filtration efficiency (at a flow rate of $84 \mathrm{~L} / \mathrm{min}$ ) and air permeability were calculated using Equations (1) and (2), respectively.

$$
\eta=\left(1-\frac{C_{\text {down }}}{C_{u p}}\right) \times 100
$$

where $\eta$ is the filtration efficiency; $C_{\text {down }}$ and $C_{u p}$ are the number concentration of particles at filter downstream and upstream, respectively.

$$
R=\frac{Q}{A} \times 167
$$

where $R$ is the air permeability of the measured materials; $Q$ is the air flow rate under 200 Pa pressure drop; and $A$ is the test area used in this test $\left(50 \mathrm{~cm}^{2}\right)$.

The quality factor (QF) was defined as follows:

$$
Q F=-\frac{\ln (1-\eta)}{\Delta P}
$$

where $\eta$ is the filtration efficiency of the filter; $\Delta P$ is the pressure drop of the airflow crossing filter.

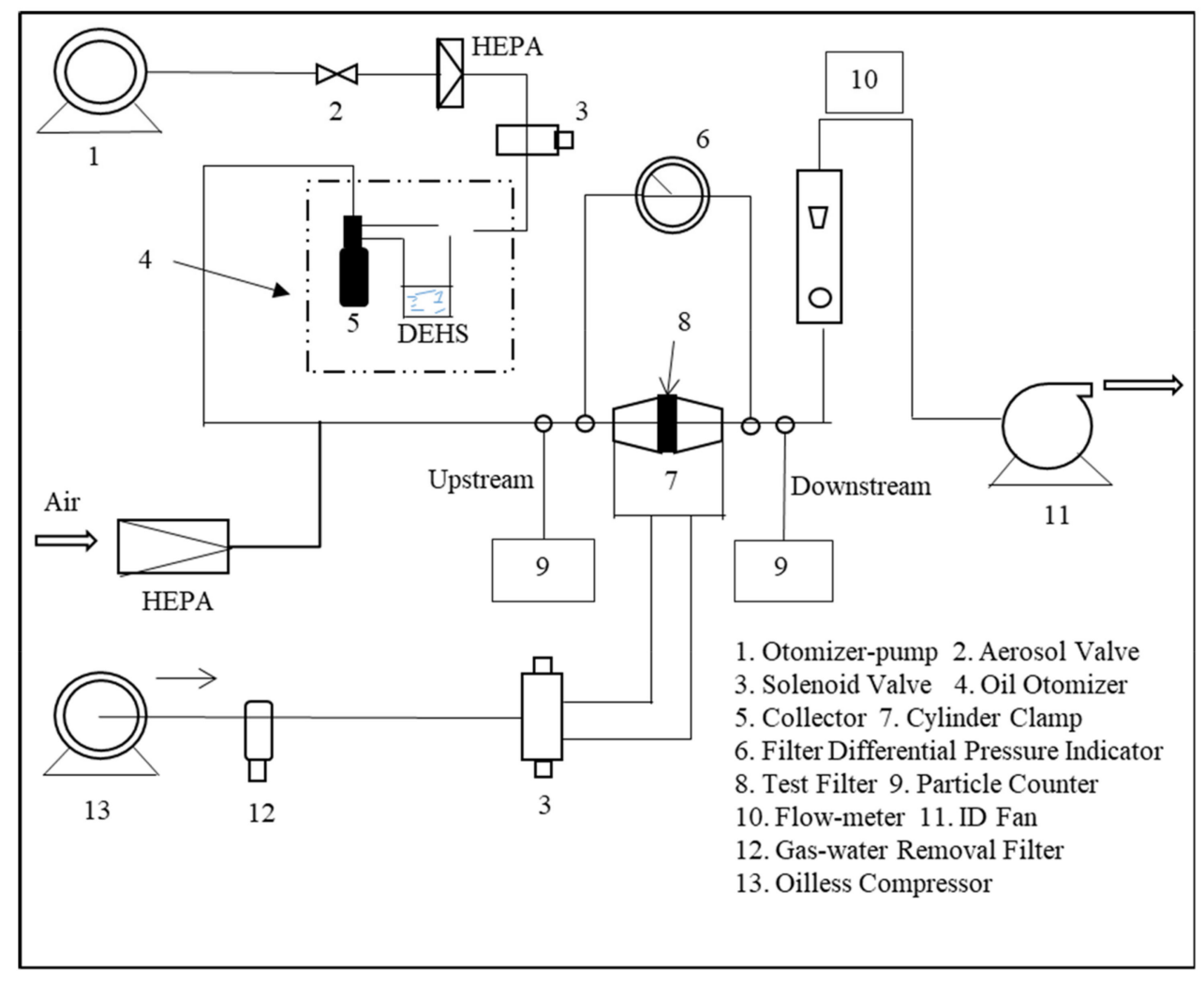

Figure 1. Experimental set-up for testing filtration efficiency. 


\section{Results and Discussion}

\subsection{Morphology of Hybrid Membranes}

$\mathrm{SiO}_{2} @ \mathrm{PI}$ hybrid nanofiber with uniform morphology was prepared via electrospinning. Herein,

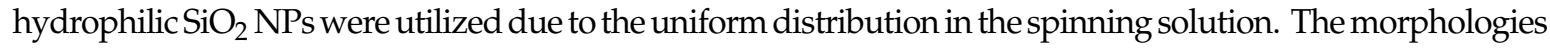
and size distribution of electrospun $\mathrm{SiO}_{2} @ \mathrm{PI}$ hybrid nanofibers embedded with different contents of $\mathrm{SiO}_{2}$ NPs $(0,1.0,1.5,2.0,3.0$, and $4.0 \%$ by wt.) are shown in Figure 2. It could be observed that pure PI nanofibers exhibit smooth surface topology with an average diameter of $229.34 \pm 55.50 \mathrm{~nm}$. The participation of $1.0 \% \mathrm{SiO}_{2} \mathrm{NPs}$ led to rough nanofibers of a relatively smaller diameter $(165.68 \pm$ $81.76 \mathrm{~nm})$. It could be found that the roughness of the nanofibers further increased and the average

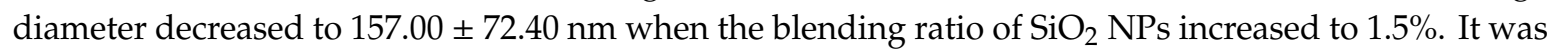
indicated that the inclusion of $\mathrm{SiO}_{2}$ NPs in PI nanofiber membranes could significantly reduce the fineness of the hybrid nanofibers, which was attributed to the weakened intermolecular Van der Waals' force between the PI molecule chains due to the existence of $\mathrm{SiO}_{2} \mathrm{NPs}$. However, some $\mathrm{SiO}_{2} \mathrm{NPs}_{\text {began }}$ to agglomerate, and the shrinkage of fiber caused by solvent volatilization did not change dramatically during electrospinning with increasing $\mathrm{SiO}_{2} \mathrm{NP}$ contents, generating large clusters on the surface, and the diameter of $\mathrm{SiO}_{2} @ \mathrm{PI}$ nanofibers increased to $385.80 \pm 169.39 \mathrm{~nm}$ when the $\mathrm{SiO}_{2}$ nanoparticle contents increased to $4.0 \%$.

Furthermore, a notable and progressive increase in the wrinkles and nano protrusions on the surface was observed with the increase in $\mathrm{SiO}_{2}$ NP contents, as shown in Figure 2, $\left(a_{1}-f_{1}\right)$ and $\left(a_{2}-f_{2}\right)$. Notably $\mathrm{SiO}_{2}$ NPs showed a uniform distribution on the surface of PI nanofibers, leaving outstanding humps and bulges on the surface. That could be awarded to phase separation induced by the fast evaporation of the solvent. The irregular surface of PI nanofibers could improve the surface roughness as well as the efficacious surface area, leading to a boost in the hydrophobicity of the $\mathrm{SiO}_{2} @ \mathrm{PI}$ hybrid membranes. As illustrated in Figure 3c, the water contact angles (WCAs) of $1.0 \% \mathrm{SiO}_{2} @ \mathrm{PI}, 1.5 \%$ $\mathrm{SiO}_{2} @ \mathrm{PI}$, and $2.0 \% \mathrm{SiO}_{2} @ \mathrm{PI}$ were $122.5,127.0$, and $130.6^{\circ}$, respectively, indicating a rise in WCAs with the adding of $\mathrm{SiO}_{2}$ NPs. According to the Wenzel model $[43,44]$, the rougher the surface was, the more hydrophobic the samples becomes. The formation of an interval distribution of $\mathrm{SiO}_{2} \mathrm{NPS}$ and PI polymer could significantly increase the hydrophobicity of the composited nanofiber. However, further increasing the content of $\mathrm{SiO}_{2}$ NPs would result in a slight decrease in WCA, which could be ascribed to the coating of hydrophilic $\mathrm{SiO}_{2}$ NPs on the surface of PI nanofibers (Figure 2, $\mathrm{e}_{1}-\mathrm{e}_{2}$ and $\mathrm{f}_{1}-\mathrm{f}_{2}$ ).

Additionally, the Knudsen number could be calculated via the following formula:

$$
K_{n}=\frac{2 \lambda}{d_{f}}
$$

where $\lambda$ and $d_{f}$ is the mean free path of air molecules $(\lambda=65.3 \mathrm{~nm})$ and fiber diameter, respectively. Accordingly, the flow regime of the gas can be divided into four different flow regimes. The free-molecular flow regime, transition flow regime, slip flow regime, and continuum flow regime (Figure 3a) [21]. Together with the fiber diameter of $\mathrm{SiO}_{2} @ \mathrm{PI}$ hybrid membranes, the air flow around PI nanofibers belongs to the transition flow regime. The corresponding $K_{n}$ values of PI, $1.0 \% \mathrm{SiO}_{2} @ \mathrm{PI}, 1.5 \% \mathrm{SiO} \mathrm{O}_{2} @ \mathrm{PI}$, 2.0\% $\mathrm{SiO}_{2} @ \mathrm{PI}, 3.0 \% \mathrm{SiO}_{2} @ \mathrm{PI}$, and 4.0\% $\mathrm{SiO}_{2} @ \mathrm{PI}$ were 0.55, 0.78, 0.83, 0.66, 0.56, and 0.34, respectively. According to the slip flow phenomenon principle (as shown in Figure $3 b$ ), when the fiber diameter got close to $65.3 \mathrm{~nm}$, the velocity of air flow was non-zero on the surface of a single fiber. Therefore, the drag force of the airstream could be reduced significantly. Thus, we could reasonably assume that the $\mathrm{SiO}_{2} @ \mathrm{PI}$ hybrid membranes showed the features of the lip-effect, especially for $1.5 \% \mathrm{SiO} 2 @ \mathrm{PI}$ hybrid membrane. 

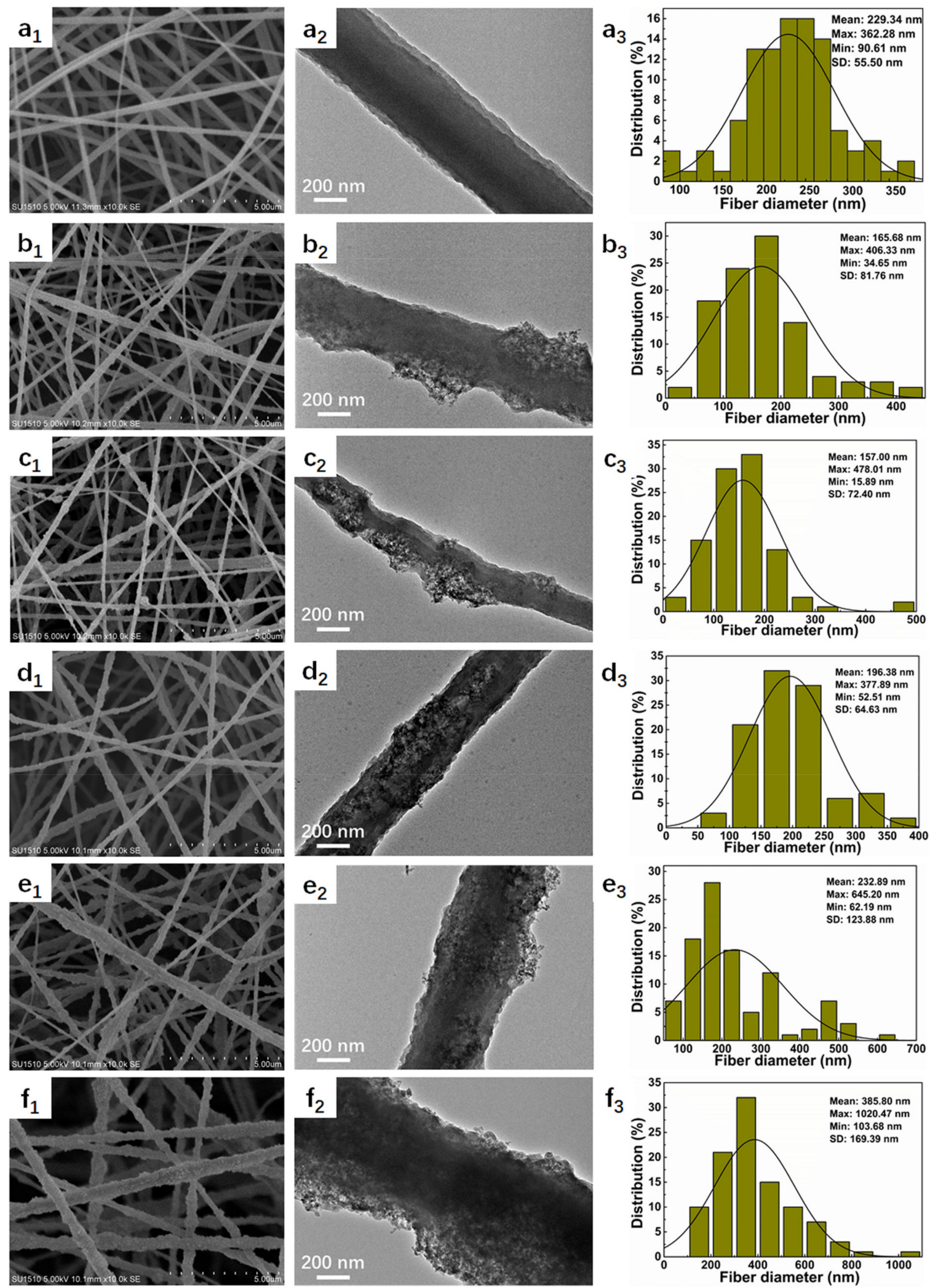

Figure 2. SEM images $\left(\mathbf{a}_{\mathbf{1}}-\mathbf{f}_{\mathbf{1}}\right)$, TEM images $\left(\mathbf{a}_{\mathbf{2}}-\mathbf{f}_{\mathbf{2}}\right)$, and fiber diameter distribution $\left(\mathbf{a}_{\mathbf{3}}-\mathbf{f}_{\mathbf{3}}\right)$ of $\mathrm{SiO}_{2} @$ polyimide (PI) hybrid membranes with different $\mathrm{SiO}_{2} \mathrm{NP}$ contents: $\left(\mathbf{a}_{\mathbf{1}}-\mathbf{a}_{3}\right) 0 \%,\left(\mathbf{b}_{\mathbf{1}}-\mathbf{b}_{3}\right) 1.0 \%,\left(\mathbf{c}_{1}-\mathbf{c}_{3}\right) 1.5 \%$, $\left(\mathbf{d}_{\mathbf{1}}-\mathbf{d}_{\mathbf{3}}\right) 2.0 \%$, $\left(\mathbf{e}_{\mathbf{1}}-\mathbf{e}_{3}\right) 3.0 \%$, and $\left(\mathbf{f}_{\mathbf{1}}-\mathbf{f}_{3}\right) 4.0 \%$. 


\begin{tabular}{|c|c|c|c|}
\hline$\underset{K_{n}=0.0001}{\longleftarrow}$ & 0.01 & 1 & 100 \\
\hline Continuum flow & Slip flow & Transition flow & Free-molecular flow \\
\hline$d_{f} \geq 130.6 \mu \mathrm{m}$ & $1.306 \mu \mathrm{m} \leq d_{f} \leq 130.6 \mu \mathrm{m}$ & $0.01306 \mu \mathrm{m} \leq d_{f} \leq 1.306 \mu \mathrm{m}$ & $d_{f} \leq 0.01306 \mu \mathrm{m}$ \\
\hline
\end{tabular}

b
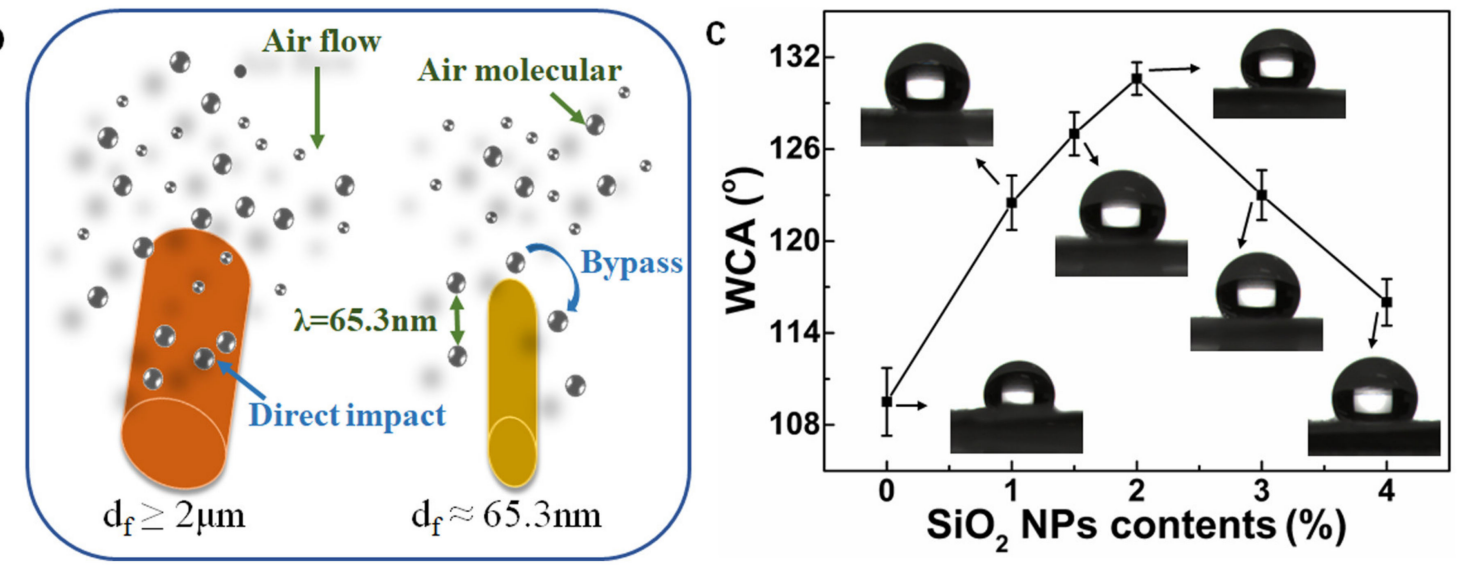

Figure 3. (a) The schematic representation of the scale bars of flow regime. (b) Schematic showing the mechanism of slip flow. (c) WCAs and the selected optical profiles of water droplets on various $\mathrm{SiO}_{2} @ P I$ hybrid membranes.

\subsection{Chemical Structure}

The as-prepared membranes were characterized by FTIR and XRD to further investigate their chemical compositions and structure. After adding $\mathrm{SiO}_{2} \mathrm{NPs}$, the main functional groups of PI at $1779,1714,1359$, and $720 \mathrm{~cm}^{-1}$ is $\mathrm{C}=\mathrm{O}$ asymmetric stretch, $\mathrm{C}=\mathrm{O}$ symmetric stretch, $\mathrm{C}-\mathrm{N}$ stretching variation, and $\mathrm{C}=\mathrm{O}$ bending variation in the resulting imide structures, respectively, and they all remained (Figure 4a) [45]. In addition, the peak intensity of the $\mathrm{O}-\mathrm{H}$ vibration band (3487-3682 $\mathrm{cm}^{-1}$ ) and $\mathrm{C}-\mathrm{H}$ band $\left(2822-3137 \mathrm{~cm}^{-1}\right)$ decreased with increasing $\mathrm{SiO}_{2} \mathrm{NP}$ contents. It was also notable that the characteristic peak of $\mathrm{Si}-\mathrm{O}$ bonds at around $1095 \mathrm{~cm}^{-1}$ might be overlaid by the $\mathrm{C}-\mathrm{O}$ bonds [46]. Additionally, it was obvious that the width of diffraction peak (around $10^{\circ}$ ) was firstly decreased when the contents of $\mathrm{SiO}_{2} \mathrm{NPs}$ increased to $1.5 \%$ and then enhanced with the further increased $\mathrm{SiO}_{2} \mathrm{NP}$ contents, as shown in Figure 4b. The results of this study were dovetailed with many experimental measurements [47-49]. The reason was that the proper contents of inorganic nanoparticles could form a tight adhesion between the NP and PI molecules. The increased width of diffraction peak was due to the inhibition of crystallization by the particle agglomeration of $\mathrm{SiO}_{2} \mathrm{NPs}$ during the solidification process.
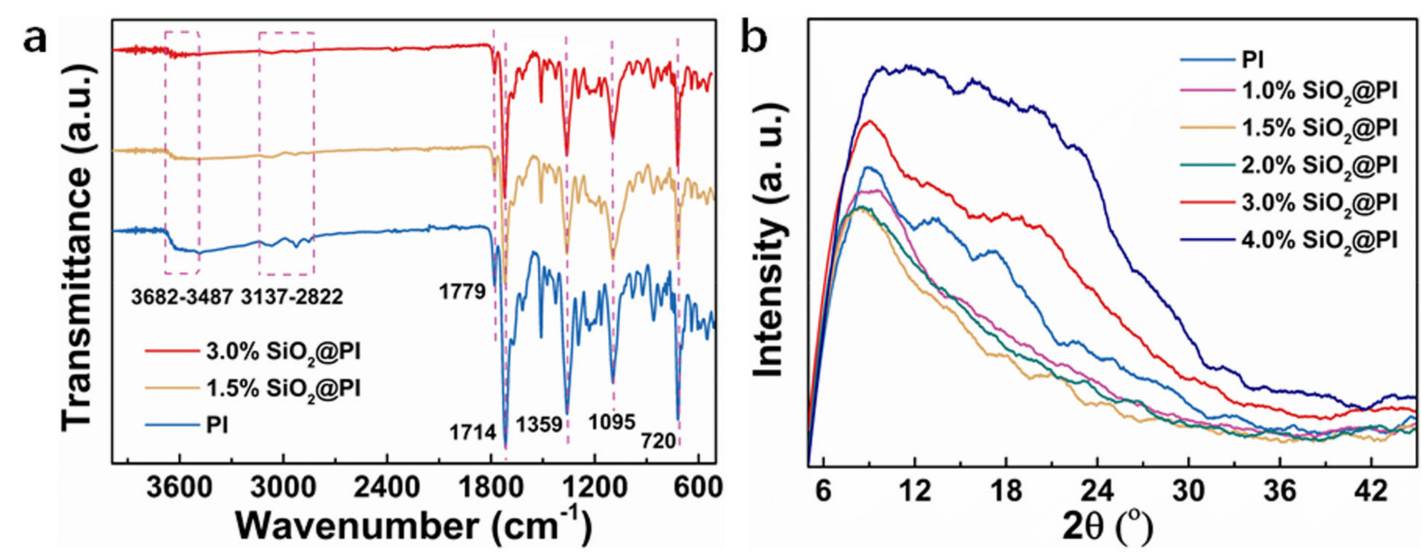

Figure 4. (a) FTIR spectra and (b) XRD patterns of PI and $\mathrm{SiO}_{2} @ P I$ hybrid membranes. 


\subsection{Thermal Performance}

Thermal stability is another crucial parameter for the safety characteristics estimation of the high-temperature filters. The thermal shrinkage behaviors of membranes were tested by heating at $220^{\circ} \mathrm{C}$ for $1 \mathrm{~h}$, as shown in Figure 5a. The PI membrane showed significant shrinking after thermal testing (about 13\%). As for the nanofiber membrane incorporated with $\mathrm{SiO}_{2} \mathrm{NPs}$, only slight shrinkage could be tested for the 1.5\% $\mathrm{SiO}_{2} @ \mathrm{PI}$ hybrid membrane (about 2.5\%), which showed a color change from white to light yellow. While $3.0 \% \mathrm{SiO}_{2} @ \mathrm{PI}$ hybrid membrane could maintain its original dimensions with less shrinkage, remaining its original color.
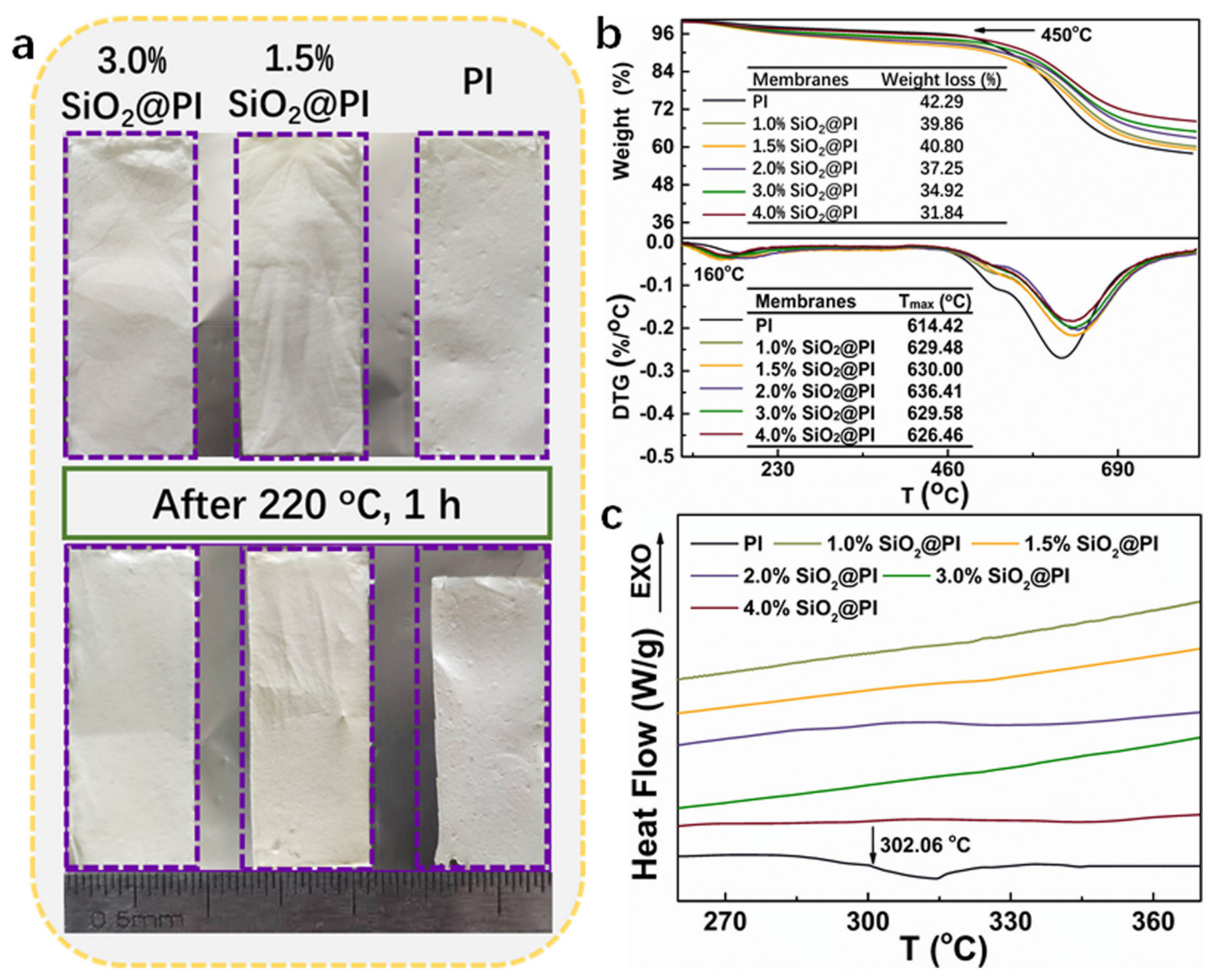

Figure 5. (a) Photos of $\mathrm{PI}$ and $\mathrm{SiO}_{2} @ \mathrm{PI}$ nanofiber membranes before and after being exposed at $220^{\circ} \mathrm{C}$ for $1 \mathrm{~h}$; TG and the differential thermogravimetric (DTG) curve (b) and differential scanning calorimeter (DSC) curves (c) of the electrospun hybrid membranes with different $\mathrm{SiO}_{2} \mathrm{NP}$ contents.

As for the quantitative study of the thermal property, TG testing was also performed (shown in Figure $5 b$ ). As observed, all the composited samples showed significant enhancement in thermal stability in comparison with a pure PI membrane, which displayed a similar mass loss behavior along with the increase in heating temperature. In the low temperature range (about $160^{\circ} \mathrm{C}$ ), the minimal weight loss was caused by the removal of residual organic solvent. Subsequently, larger weight loss was detected at around $450{ }^{\circ} \mathrm{C}$, which was mainly due to the self-crosslinking, cyclization, and dehydrogenation of the membranes. As the temperature increased, the exothermic peaks appeared at $630^{\circ} \mathrm{C}$ (maximum degradation rate temperature, $\mathrm{T}_{\max }$ ), which was ascribed to the continuous release of the oxidation of carbon and carbon monoxide. The $\mathrm{T}_{\max }$ values of the $\mathrm{SiO}_{2} @ \mathrm{PI}$ composites firstly increased to $636.41^{\circ} \mathrm{C}$ for $2.0 \% \mathrm{SiO}_{2} @ \mathrm{PI}$ composites and then decreased to $626.46^{\circ} \mathrm{C}$ for $4.0 \% \mathrm{SiO}_{2} @ \mathrm{PI}$ composites, which were 
all higher than that of the PI nanofiber. The enhancement of the thermal stability could be attributed to the introduction of thermal stable $\mathrm{SiO}_{2} \mathrm{NPs}$. Additionally, the interaction and physical interpenetration of $\mathrm{SiO}_{2} \mathrm{NPs}$ were further strengthened on a nanometer or even molecular level after electrospinning into nanofibers. Thereby, the decomposition of polyimide might be delayed by the incorporation of $\mathrm{SiO}_{2} \mathrm{NPs}$. Additionally, it is noted that in the systems where the silica phase had no chemical bonding or other interactions with the polymer, only a small thermal stability improvement was observed. After heating up to $800^{\circ} \mathrm{C}$, the weight dropped to the lowest, manifesting the complete combustion and decomposition of PI molecules. However, in the present study, the residual weight after being heated at $800{ }^{\circ} \mathrm{C}$ increased with the rise in the $\mathrm{SiO}_{2} \mathrm{NP}$ contents, which was much higher than the incorporated $\mathrm{SiO}_{2} \mathrm{NP}$ percentage. These results also confirmed the successful incorporation of the $\mathrm{SiO}_{2}$ moiety in the hybrid membranes and its positive effects on the PI stability. The thermal behavior of hybrid membranes was also evaluated by DSC measurements (Figure 5c). The PI and $\mathrm{SiO}_{2} @ \mathrm{PI}$ hybrid membranes showed no significant peaks from $30^{\circ} \mathrm{C}$ to $400{ }^{\circ} \mathrm{C}$, indicating excellent thermal stability in the medium and low temperature environment.

\subsection{Mechanical Property}

As shown in Figure 6a, it was obvious that the strength of the $\mathrm{SiO}_{2} @ P I$ hybrid membranes was promoted as the $\mathrm{SiO}_{2}$ content increased from 0 to $1.5 \mathrm{wt} . \%$, and the $\mathrm{SiO}_{2} @ \mathrm{PI}$ hybrid membranes with $1.5 \mathrm{wt} . \% \mathrm{SiO}_{2} \mathrm{NPs}$ performed the highest tensile strength $(1216.4 \mathrm{kPa}, 33 \%$ enhancement compared to the pure PI membrane) among all samples. It could be concluded that the addition of $\mathrm{SiO}_{2} \mathrm{NPs}$ effectively improved the strength of PI nanofiber membrane. Since the inorganic nanoparticles $\left(\mathrm{SiO}_{2}\right)$ incorporating inside PI nanofibers could play a crucial role in absorbing extra energy and dispersing strength during stretching process. However, when the loading of $\mathrm{SiO}_{2} \mathrm{NPs}$ increased from 2.0 to $4.0 \mathrm{wt} . \%$, the tensile strength dropped significantly by more than $68 \%$, due to the $\mathrm{SiO}_{2} \mathrm{NP}$ agglomeration, which broke the continuity of the PI molecule along the PI nanofiber, causing weak sections in the nanofiber structure. In addition, all $\mathrm{SiO}_{2} @ \mathrm{PI}$ hybrid membranes possessed lower tensile strains than pristine PI membranes, which is attributed to the introduction of $\mathrm{SiO}_{2} \mathrm{NPs}$ into PI nanofibers, leading to slightly less flexibility. As shown in Figure 6b, Young's Modulus of $\mathrm{SiO}_{2} @ P I$ hybrid membranes increased firstly and then decreased sharply with increased $\mathrm{SiO}_{2} \mathrm{NP}$ contents. It should be attributed to the polymer-filler interaction and reduced packing density (Figure 2).
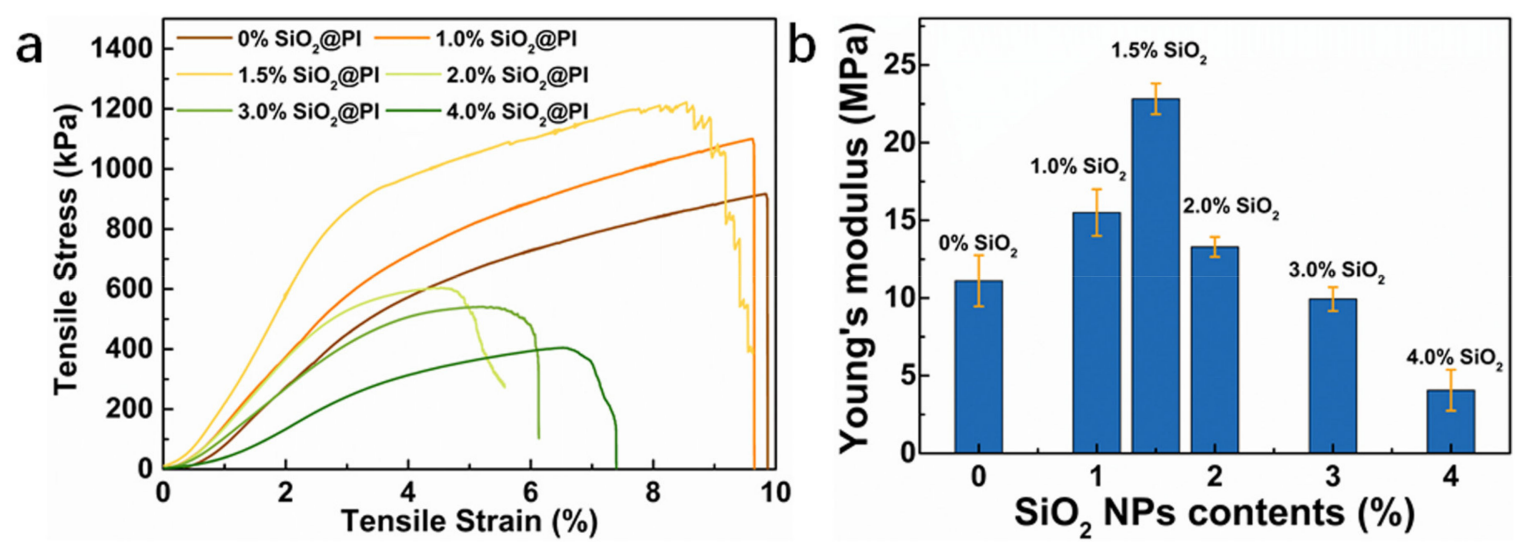

Figure 6. Mechanical characterization of $\mathrm{SiO}_{2} @ P I$ hybrid membranes: (a) tensile stress-strain curves; (b) Young's Modulus.

\subsection{Porous Structure}

It is widely believed that porous structure has a crucial impact on the filtration performance of fibrous materials. Herein, to investigate the influence of $\mathrm{SiO}_{2} \mathrm{NP}$ contents on the filtration performance of filters, the porous structures and pore size of all hybrid membranes were studied. As illustrated in 
Figure 7, the pore sizes of all $\mathrm{SiO}_{2} @ \mathrm{PI}$ hybrid membranes were in the range of $1.70-5.06 \mu \mathrm{m}$, which were higher than that of pure PI membranes $(1.37 \mu \mathrm{m})$, which was mainly due to the introduction of $\mathrm{SiO}_{2}$ NPs resulting in the reduction in the packing density of membrane. The results also suggested that the maximum and mean pore size firstly decreased and then rose with the increasing $\mathrm{SiO}_{2} \mathrm{NP}$ contents. Pore size was positively correlated to the fiber diameter of relevant membranes (Figure 2). Meanwhile, the microstructure and interconnectivity of the pores could be characterized by the bubble point pressure, which firstly rose from 1.329 to $2.479 \mathrm{psi}$ and then reduced to 0.329 psi with the increasing $\mathrm{SiO}_{2} \mathrm{NP}$ contents. The increase in the bubble point pressure of relevant membranes could be owing to the smallest fiber diameter and more $\mathrm{SiO}_{2} \mathrm{NPs}$ protruding from the surfaces of fibers, or the interspace among the fibers could significantly improve the complexity of the hybrid membrane pore structure. Additionally, when further increasing $\mathrm{SiO}_{2} \mathrm{NP}$ content, the increasing maximum pore size causing the value of the bubble point pressure decreased.
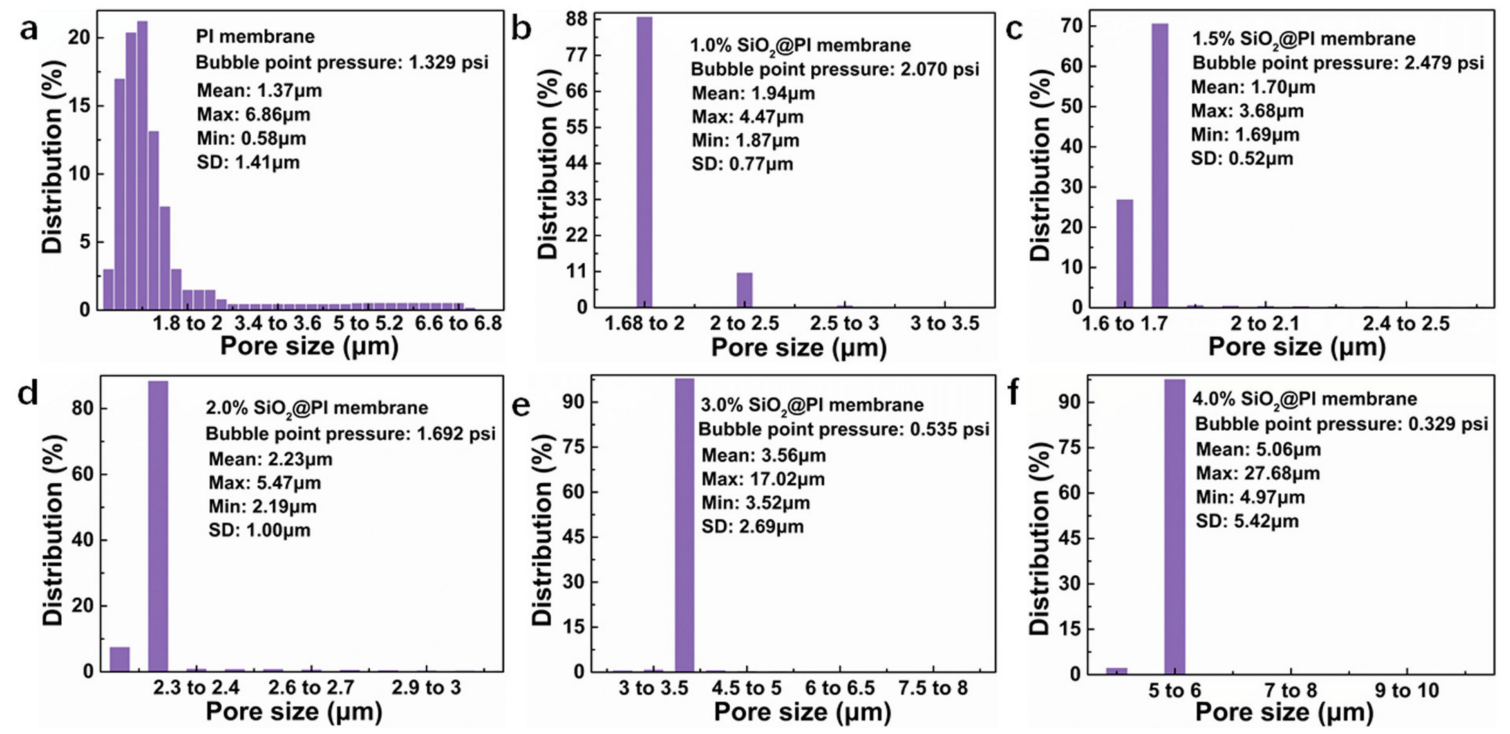

Figure 7. Pore sizes and their distributions of various $\mathrm{SiO}_{2} @ \mathrm{PI}$ hybrid membranes. (a) PI, (b) $1.0 \%$ $\mathrm{SiO}_{2} @ \mathrm{PI},(\mathbf{c}) 1.5 \% \mathrm{SiO}_{2} @ \mathrm{PI},(\mathbf{d}) 2.0 \% \mathrm{SiO}_{2} @ \mathrm{PI},(\mathbf{e}) 3.0 \% \mathrm{SiO}_{2} @ \mathrm{PI}$, and (f) $4.0 \% \mathrm{SiO}_{2} @ \mathrm{PI}$.

\subsection{Filtration Performance}

The filtration performance of charge neutralized dioctyl sebacate (DEHS) particles in $0.3,0.5$, and $1.0 \mu \mathrm{m}\left(\mathrm{PM}_{0.3}, \mathrm{PM}_{0.5}\right.$, and $\left.\mathrm{PM}_{1.0}\right)$ for different needle-punched PPS composite filters were tested (Figure 8). Figure $8 \mathrm{~b}$ presents the filtration efficiency and pressure drop of the pure needle-punched PPS filter (PPS), polytetrafluoroethylene (PTFE) emulsion impregnated PPS composite filter (PPS-PTFE), PI nanofiber membrane composite filter (PPS-PI), and $\mathrm{SiO}_{2} @ P I$ hybrid nanofiber membrane composite filter (PPS-SiO ${ }_{2} @ \mathrm{PI}$ ) at the airflow velocity of $84 \mathrm{~L} / \mathrm{min}$. It was visible that both the filtration efficiency and pressure drop of the PPS composite filters were higher than that of the pure PPS filter, especially for the PPS-PI and PPS-SiO${ }_{2} @ P I$ filters. Meaningfully, the PPS-SiO ${ }_{2} @ P I$ filter showed the best filtration performance compared with the other filters (Figure 8c), indicating that $\mathrm{SiO}_{2} \mathrm{NPs}$ could capture more charges due to the permanent dipole orientation character of $\mathrm{SiO}_{2} \mathrm{NPs}$.

In corroboration of the superiority of PPS-SiO ${ }_{2} @ \mathrm{PI}$ composite filters as filter media, the filtration performance of PPS-SiO $\mathrm{SPI}_{2}$ composite filters was further optimized by doping different $\mathrm{SiO}_{2}$ NP content (PPS-PI, PPS-1.0\%SiO $\mathrm{S}_{2} @ \mathrm{PI}, \mathrm{PPS}-1.5 \% \mathrm{SiO}_{2} @ \mathrm{PI}, \mathrm{PPS}-2.0 \% \mathrm{SiO}_{2} @ \mathrm{PI}, \mathrm{PPS}-3.0 \% \mathrm{SiO}_{2} @ \mathrm{PI}$, and PPS-4.0\% $\left.\mathrm{SiO}_{2} @ \mathrm{PI}\right)$. As shown in Figure 8d and e, it could be observed that both filtration efficiency

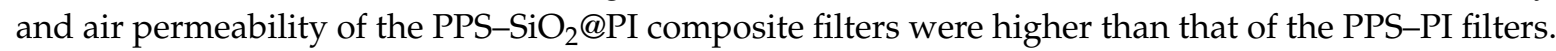
Compared with the PPS-PI filters, all PPS-SiO $\mathrm{S}_{2} @ P I$ composite filters had a modest increase (14 23\%) in filtration efficiency for $\mathrm{PM}_{0.3}$. We also found that the filtration efficiency of $\mathrm{PM}_{0.3}$ was more than 
$85 \%$ for the PPS-SiO $\mathrm{SiPI}_{2}$ composite filters, especially for PPS-1.5\% $\mathrm{SiO}_{2} @ \mathrm{PI}$ filters (94.378\%), while that of PPS-PI was only $71.501 \%$. However, the pressure drop illustrated a contrary trend by adding $\mathrm{SiO}_{2} \mathrm{NPs}$. The nano-protrusions formed by the inorganic nanoparticles could raise the projected frontal areas of nanofibers at the inlet and impose a pressure gradient due to the increased tortuosity, which allowed the penetration of air flow partly and intercepted PM effectively (Figure 8a). For the PPS-SiO ${ }_{2} @ P I$ composite filters, as mentioned above, the fiber diameter and mean pore size of the $\mathrm{SiO}_{2} @ \mathrm{PI}$ hybrid membranes decreased and the intercellular structure became more complex as the $\mathrm{SiO}_{2} \mathrm{NP}$ contents rose from 1.0 to $1.5 \%$, contributing to the improvement of the filtration efficiency of PPS-SiOn $@ P I$ composite filters, especially for $\mathrm{PM}_{0.3}$. When the $\mathrm{SiO}_{2} \mathrm{NP}$ contents were over $2.0 \%$, the filtration efficiency of PPS-SiO${ }_{2} @ P I$ composite filters reduced due to the increase in fiber diameter and pore size. To perform the overall evaluation of the filtration performances, quality factor $(\mathrm{QF})$, a parameter that considers both filtration efficiency and pressure drop, were further calculated. Results showed that when the $\mathrm{SiO}_{2} \mathrm{NP}$ contents increased from 0 to $1.5 \%$, the QF value of the composite filters for $\mathrm{PM}_{0.3}, \mathrm{PM}_{0.5}$, and $\mathrm{PM}_{1.0}$ improved. However, when the $\mathrm{SiO}_{2} \mathrm{NP}$ contents continued to increase to $4.0 \%$, the QF value reduced (Figure $8 \mathrm{f}$ ). Notably, compared with the other PPS-SiO $@$ @PI composite filters, the PPS-1.5\% $\mathrm{SiO}_{2} @ \mathrm{PI}$ filters enjoyed a relatively higher QF value of 0.029 for $\mathrm{PM}_{1.0}$, indicating outstanding filtration performances for particles with a small diameter and great potential application in polluted air purification. Further investigation of the PPS-SiO ${ }_{2} @ \mathrm{PI}$ composite filters was conducted on the membrane with $1.5 \% \mathrm{SiO}_{2} \mathrm{NPs}$ as the optimal condition.
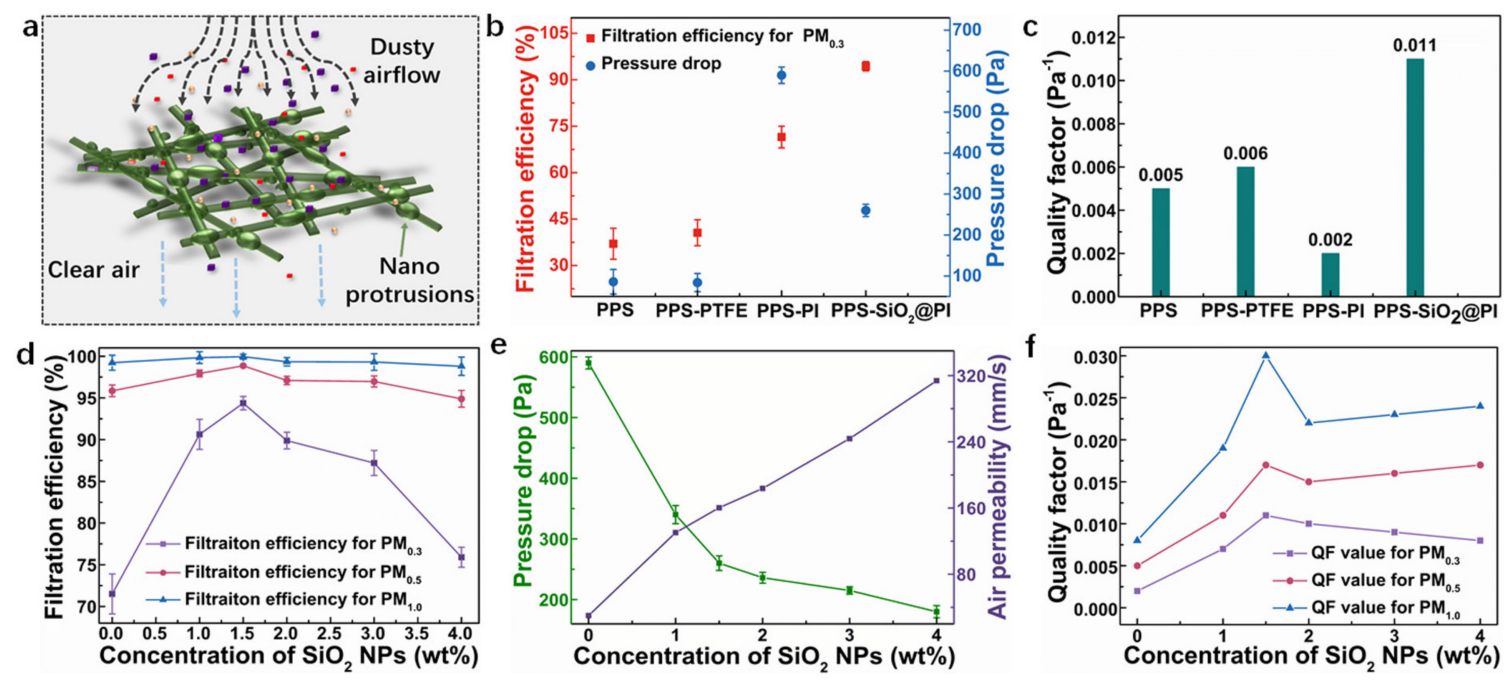

Figure 8. (a) The schematic diagram of air filtration through polyphenylene sulfide (PPS) $-\mathrm{SiO}_{2} @ P I$ composite filters; filtration performance (b) and quality factor (QF) values (c) of different kinds of PPS filters; filtration efficiency (d), pressure drop and air permeability (e), and QF values (f) of relevant PPS-SiO ${ }_{2} @ P I$ composite filters for $\mathrm{PM}_{0.3}, \mathrm{PM}_{0.5}$, and $\mathrm{PM}_{1.0}$.

\subsection{Filtration Efficiency and Reusability of Welded Composite Filters}

Results indicated that the filtration efficiency of welded PPS-1.5\% $\mathrm{SiO}_{2} @ P I$ filters for all particles exceeded $90 \%$, slightly smaller than that of the unwelded PPS-1.5\%SiO $\mathrm{SPI}_{2}$ filters (Figure 9a). It could be attributed to the slight increase in the average pore size from 1.70 to $1.77 \mu \mathrm{m}$ after welding (Table 1 ). The changes in pore structure were evaluated by comparing the pore size of the composite filters before and after welding (Figure $9 \mathrm{~b})$. The number of the smaller pores $(\sim 1.68-2.00 \mu \mathrm{m})$ was slightly reduced when the filter was welded, corresponding to the increase in the overall mean pore size. In addition, Figure $9 \mathrm{~b}$ indicated that large pores $(3.5-4.5 \mu \mathrm{m})$ could be created as a result of solvent-vapor treatment. This was probably due to the fact that, during the welding process, PI nanofibers would be softened, and those with a smaller diameter were dragged to the adhesive onto the bigger ones, 
which would drag the fibers closer to each other and leave more local free volumes or bigger pores (as shown in Figure 9c,d). Moreover, the reduced bubble point pressure from $2.479 \mu \mathrm{m}$ to $0.930 \mu \mathrm{m}$ after welding was also supporting the change in pore structure. In addition, the synergistic effects of vapor-welding and $\mathrm{SiO}_{2} \mathrm{NPs}$ joining on the strength enhancement were studied. An increase in tensile strength (from $1216.40 \mathrm{kPa}$ to $1547.49 \mathrm{kPa}$ ) of the welded 1.5\% $\mathrm{SiO}_{2} @ \mathrm{PI}$ membrane could be confirmed (Figure 9e). The percentage of enhancement in the strength was 27\%, compared to that of the unwelded $1.5 \% \mathrm{SiO}_{2} @ \mathrm{PI}$ membrane. The improved mechanical strength could be attributed to the inter-bonding of fibers at the cross points in-plane as well as in vertical-to-plane directions, which restricted mat delamination. Moreover, it was found that the tensile strength enjoyed a 70\% enhancement, compared to the pure PI nanofiber membrane (Figure 6a). The improvement in mechanical strength by the combination of welding and $\mathrm{SiO}_{2}$ NPs reinforcement was more pronounced than that of a single strategy. More importantly, although the elongation of the PI membrane reduced after adding $\mathrm{SiO}_{2}$ $\mathrm{NPs}$, the elongation of the $\mathrm{SiO}_{2} @ \mathrm{PI}$ membrane could be compensated by solvent-vapor treatment in this work.

Reusability of welded PPS-1.5\% $\mathrm{SiO}_{2} @$ PI filters was determined by conducting a 20-cycle filtration for various particle sizes $\left(\mathrm{PM}_{0.3}, \mathrm{PM}_{0.5}\right.$, and $\left.\mathrm{PM}_{1.0}\right)$, as shown in Figure 9 f. Filtration efficiency for $\mathrm{PM}_{1.0}$ remained higher than $99 \%$ during the 20 filtration testing cycles. In the case of the $\mathrm{PM}_{0.3}$, the efficiency $>95 \%$ could be obtained after nine filtration cycles. It was suggested that high-performance filtration of the welded PPS-1.5\% $\mathrm{SiO}_{2} @ \mathrm{PI}$ filters could maintain for at least 20 cycles. It should be noticed that the increase in filtration efficiency for $\mathrm{PM}_{0.3}$ was attributed to the particles that strongly attached to the membrane surface with increasing filtration cycles. The accumulation of particles in the filters would block more particles trying flow through the pores, thereby filtration efficiency was increased. Most notably, the pressure drops of welded PPS-1.5\% $\mathrm{SiO}_{2} @ P I$ filters had almost no change for 20 testing cycles, which could be explained by the fact that most particles were attached to the fiber surface due to the electrostatic interaction but not tightly accumulated in the pores of the filters. The robustness of the filter in long-term usage was attested. In addition, the hybrid filter prepared in this study possessed comparable or higher filtration efficiency to other electrospun inorganic NP-filled polymer hybrid filters [27,50-52], as shown in Figure 10.
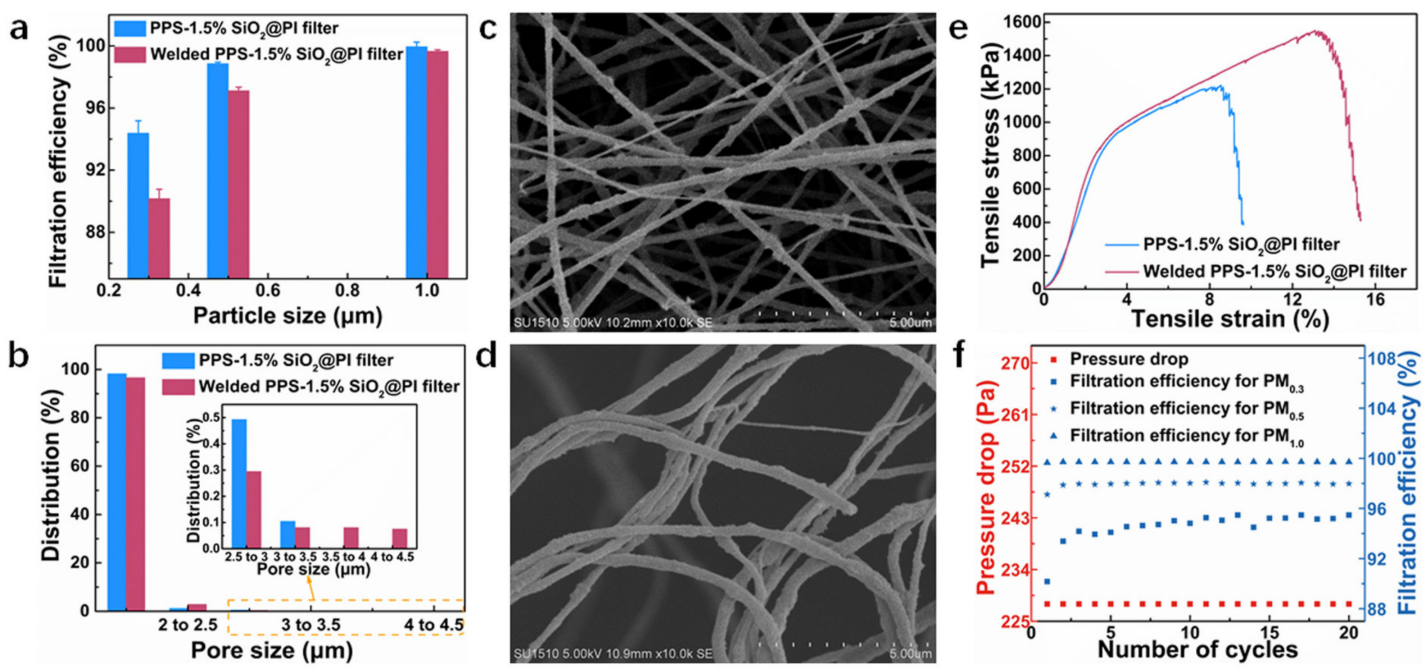

Figure 9. Filtration efficiency (a), pore size and its distribution (b), and tensile stress-strain curves (e) before and after welded PPS-1.5\%SiO $\mathrm{SPI}_{2} @$ filters; SEM images of PPS-1.5\%SiO ${ }_{2} @ P I$ filters before (c) and after (d) being welded by solvent vapor; (f) filtration efficiency of welded PPS-1.5\%SiO $\mathrm{OPI}_{2}$ filters in 20 cycles. 
Table 1. Characteristics of PPS-1.5\%SiO $@$ PI filters before and after being welded by solvent vapor.

\begin{tabular}{ccccc}
\hline Filters & $\begin{array}{c}\text { Mean Pore Size } \\
(\mu \mathrm{m})\end{array}$ & $\begin{array}{c}\text { Maximum Pore Size } \\
(\mu \mathrm{m})\end{array}$ & $\begin{array}{c}\text { Bubble Point Pressure } \\
(\mathbf{p s i})\end{array}$ & $\begin{array}{c}\text { Pressure Drop } \\
(\text { Pa) }\end{array}$ \\
\hline PPS-1.5\%SiO${ }_{2} @ \mathrm{PI}$ & 1.70 & 3.68 & 2.479 & 260 \\
Welded PPS-1.5\%SiO $\mathrm{Si}_{2} @ \mathrm{PI}$ & 1.77 & 7.98 & 0.930 & 243 \\
\hline
\end{tabular}

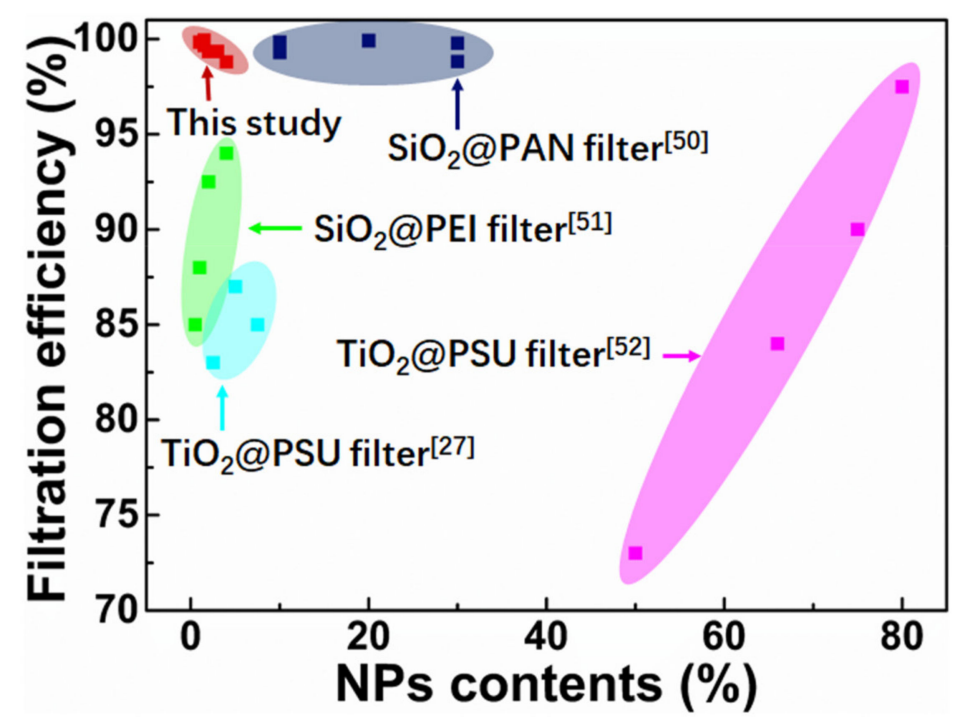

Figure 10. Ashby plot of NP contents versus filtration efficiency for other inorganic NP-filled polymer hybrid filters.

\section{Conclusions}

In this study, we have brought out an approach to improve the mechanical strength of PI nanofibrous membranes via a combination of solvent-vapor-induced welding and $\mathrm{SiO}_{2} \mathrm{NP}$ reinforcement. The results showed that the $\mathrm{SiO}_{2}$ NPs distributed in the surfaces of PI nanofibers could generate hierarchical structures, which not only enhanced the mechanical properties but also promoted the filtration performance of composite filters. More importantly, the mechanical properties and filtration performance could be further tuned by adjusting the $\mathrm{SiO}_{2} \mathrm{NP}$ content, and the welded $1.5 \% \mathrm{SiO}_{2} @ \mathrm{PI}$ showed the most balanced property (the increase in tensile strength and filtration efficiency by 70 and $20 \%$, respectively). The reusability of the welded PPS-1.5\%SiO $@ P I$ composite filter for filtration of $\mathrm{PM}_{0.3}, \mathrm{PM}_{0.5}$ and $\mathrm{PM}_{1.0}$ was confirmed, as the filtration efficiency was maintained at at least $90 \%$ and up to nearly $100 \%$ without increasing the pressure drop after the 20 filtration testing cycles. Therefore, it is promising to employ this new route for the preparation of mechanically strengthened electrospun materials with high-performance air filtration.

Author Contributions: Conceptualization: D.L., Y.S., Q.L., and B.D.; methodology: D.L., Y.S., and B.D.; software: D.L. and Y.S.; validation: D.L., Y.S., L.W., and F.L.; formal analysis: D.L. and Y.S.; investigation: D.L. and Y.S.; resources: D.L. and Y.S.; data curation: D.L. and Y.S.; writing—original draft preparation: D.L. and Y.S.; writingreview and editing: D.L. and Y.S.; visualization: D.L., Y.S., L.W., F.L., and Q.L.; supervision: D.L. and B.D.; project administration: D.L. and B.D.; funding acquisition: D.L. and B.D. All authors have read and agreed to the published version of the manuscript.

Funding: This research study was supported by the Postgraduate Research \& Practice Innovation Program of Jiangsu Provence (KYCX18_1823), National Natural Science Foundation of China (NO. 51908246), Fundamental Research Funds for the Central Universities (NO. JUSRP51907A), the National Key Research and Development Program of China (No.2019YFC1904502), China Postdoctoral Science Foundation (2019M651699), National Defense Cultivation Project of Fundamental Research Funds for the Central Universities (JUSRP41904).

Acknowledgments: Instrument Analysis Centre of School of Textiles and Clothing, Jiangnan University, is gratefully acknowledged for all the equipment employed.

Conflicts of Interest: The authors declare no conflict of interest. 


\section{References}

1. Xie, Y.; Zhao, B.; Zhang, L.; Luo, R. Spatiotemporal variations of $\mathrm{PM}_{2.5}$ and $\mathrm{PM}_{10}$ concentrations between 31 Chinese cities and their relationships with $\mathrm{SO}_{2}, \mathrm{NO}_{2}, \mathrm{CO}$ and $\mathrm{O}_{3}$. Particuology 2015, 20, 141-149. [CrossRef]

2. Miao, H.; Takamichi, I.; Makoto, K. Differences in allergic inflammatory responses between urban $\mathrm{PM}_{2.5}$ and fine particle derived from desert-dust in murine lungs. Toxicol. Appl. Pharmacol. 2016, 297, 41-55.

3. Afghan, F.R.; Patidar, S.K. Health impacts assessment due to $\mathrm{PM}_{2.5}, \mathrm{PM}_{10}$ and $\mathrm{NO}_{2}$ exposure in national capital territory (NCT) delhi. Pollution 2020, 6, 115-126.

4. Xu, Y.; Yang, L.; Wang, X.; Zheng, M.; Li, C.; Zhang, A.; Fu, J.; Yang, Y.; Qin, L.; Liu, X.; et al. Risk evaluation of environmentally persistent free radicals in airborne particulate matter and influence of atmospheric factors. Ecotox. Environ. Safe 2020, 196, 110571. [CrossRef] [PubMed]

5. Xiao, J.; Liang, J.; Zhang, C.; Tao, Y.; Ling, G.; Yang, Q. Advanced materials for capturing particulate matter: Progress and perspectives. Small Methods 2018, 2, 1800012. [CrossRef]

6. Kadam, V.V.; Wang, L.; Padhye, R. Electrospun nanofiber materials to filter air pollutants-A review. J. Ind. Text. 2018, 47, 2253-2280. [CrossRef]

7. Liu, J.; David, Y.; Pui, H.; Wang, J. Removal of airborne nanoparticles by membranes coated filters. Sci. Total. Environ. 2011, 409, 4868-4874. [CrossRef]

8. Yang, Y.; Zhang, S.; Zhao, X.; Yu, J.; Ding, B. Sandwich structured polyamide-6/polyacrylonitrile nanonets/ bead-on-string composite membrane for effective air filtration. Sep. Purif. Technol. 2015, 152, 14-22. [CrossRef]

9. Das, D.; Das, S.; Ishtiaque, S.M. Optimal design of nonwoven air filter media: Effect of fiber shape. Fiber. Polym. 2014, 15, 1456-1461. [CrossRef]

10. Lee, Y.; Wadsworth, L.C. Structure and filtration properties of melt blown polypropylene webs. Polym. Eng. Sci. 1990, 30, 1413-1419. [CrossRef]

11. Yu, Y.; Xiong, S.; Huang, H.; Zhao, L.; Nie, K.; Chen, S.; Xu, J.; Yin, X.; Wang, H.; Wang, L. Fabrication and application of poly (phenylene sulfide) ultrafine fiber. React. Funct. Polym. 2020, 150, 104539. [CrossRef]

12. Yu, B.; Han, J.; He, X.; Xu, G.; Ding, X. Effects of tourmaline particles on structure and properties of polypropylene filtration melt-blown nonwoven electrets. J. Macromol. Sci. B. 2012, 51, 619-629. [CrossRef]

13. Zhu, X.; Dai, Z.; Xu, K.; Zhao, Y.; Ke, Q. Fabrication of multifunctional filters via online incorporation nano- $\mathrm{TiO}_{2}$ into spun-bonded/melt-blown nonwovens for air filtration and toluene degradation. Macromol. Mater. Eng. 2019, 304, 1900350. [CrossRef]

14. Katarzyna, M.; Malgorzata, O.; Anita, J.; Justyna, S.; Beata, G. Microbial growth on dust-loaded filtering materials used for the protection of respiratory tract as a factor affecting filtration efficiency. Int. J. Environ. Res. Public Health 2018, 15, 1902-1920.

15. Dixit, P.; Ishtiaque, S.M.; Roy, R. Influence of sequential punching in layered structure of needle punched nonwoven on the filtration behavior. Compos. Part B Eng. 2020, 182, 107564. [CrossRef]

16. Wang, Y.X.; Xu, Y.K.; Wang, D.; Zhang, Y.J.; Zhang, X.; Liu, J.C.; Zhao, Y.; Huang, C.; Jin, X.Y. Polytetrafluoroethylene/ polyphenylene sulfide needle-punched triboelectric air filter for efficient particulate matter removal. ACS Appl. Mater. Interfaces 2019, 11, 48437-48449. [CrossRef]

17. Thakur, R.; Das, D.; Das, A. Electret air filters. Sep. Purif. Rev. 2013, 42, 87-129. [CrossRef]

18. Xiao, H.M.; Song, Y.P.; Chen, G.J. Correlation between charge decay and solvent effect for melt-blown polypropylene electret filter fabrics. J. Electrost. 2014, 72, 311-314. [CrossRef]

19. Li, Y.Y.; Yin, X.; Yu, J.Y.; Ding, B. Electrospun nanofibers for high-performance air filtration. Compos. Commun. 2019, 15, 6-19. [CrossRef]

20. Ye, B.; Wang, S.; Zhang, L.; Chen, C. Influence of fiber diameter, filter thickness, and packing density on $\mathrm{PM}_{2.5}$ removal efficiency of electrospun nanofiber air filters for indoor applications. Build. Environ. 2020, $170,106628$.

21. Li, P.; Wang, C.Y.; Zhang, Y.Y.; Wei, F. Air filtration in the free molecular flow regime: A review of highefficiency particulate air filters based on carbon nanotubes. Small 2014, 10, 4543-4561. [CrossRef] [PubMed]

22. Pafal, P.; Leon, G. Deposition and filtration of nanoparticles in the composites of nano- and microsized fibers. Aerosol. Sci. Tech. 2008, 42, 483-493.

23. Zhao, X.L.; Wang, S.; Yin, X.; Yu, J.; Ding, B. Slip-effect functional air filter for efficient purification of $\mathrm{PM}_{2.5}$. Sci. Rep. UK 2016, 6, 35472-35483. [CrossRef] 
24. Maze, B.; Tafreshi, H.V.; Wang, Q.; Pourdeyhimi, B. A simulation of unsteady-state filtration via nanofiber media at reduced operating. J. Aerosol. Sci. 2007, 38, 550-571. [CrossRef]

25. Thenmozhi, S.; Dharmaraj, N.; Kadirvelu, K.; Kim, H.Y. Electrospun nanofibers: New generation materials for advanced applications. Mat. Sci. Eng. B 2017, 217, 36-48. [CrossRef]

26. Nam, C.; Lee, S.; Ryu, M.; Lee, J.; Lee, H. Electrospun nanofiber filters for highly efficient $\mathrm{PM}_{2.5}$ capture. Korean J. Chem. Eng. 2019, 36, 1565-1574. [CrossRef]

27. Su, J.F.; Yang, G.H.; Cheng, C.L.; Huang, C.; Xu, H.; Ke, Q.F. Hierarchically structured $\mathrm{TiO}_{2} / \mathrm{PAN}$ nanfibrous membranes for high-efficiency air filtration and toluene degradation. J. Colloid Interface Sci. 2017, 507, 386-396. [CrossRef] [PubMed]

28. Yanilmaz, M.; Lu, Y.; Dirican, M.; Fu, K.; Zhang, X. Nanoparticle-on-nanofiber hybrid membrane separators for lithium-ion batteries via combining electrospraying and electrospinning techniques. J. Mater. Sci. 2014, 456, 57-65. [CrossRef]

29. Benykhlef, S.; Bekhoukh, A.; Berenguer, R.; Benyoucef, A.; Morallon, E. PANI-derived polymer $/ \mathrm{Al}_{2} \mathrm{O}_{3}$ nanocomposites: Synthesis, characterization, and electrochemical studies. Colloid Polym. Sci. 2016, 294, 1877-1885. [CrossRef]

30. Mescheder, U.; Müller, B.; Baborie, S.; Urbanovic, P. Properties of $\mathrm{SiO}_{2}$ electret films charged by ion implantation for MEMs-based energy harvesting systems. J. Micromech. Microeng. 2009, 19, 094003. [CrossRef]

31. Liu, F.; Li, M.; Shao, W.; Yue, W.; Hu, B.; Weng, K.; Chen, Y.; Liao, X.; He, J. Preparation of a polyurethane electret nanofiber membrane and its air-filtration performance. J. Colloid Interface Sci. 2019, 557, 318-327. [CrossRef] [PubMed]

32. Yu, Y.; Tan, Z.; Zhang, J.; Liu, G. Microstructural evolution and mechanical investigation of hot stretched graphene oxide reinforced polyacrylonitrile nanofiber yarns. Polym. Adv. Technol. 2020, 31, 1935-1945. [CrossRef]

33. Korkmaz, M.N.; Gizem, K.; Demet, Y. Development of a novel hybrid yarn production process for functional textile products. J. Ind. Text. 2019, 48, 1462-1488. [CrossRef]

34. Homocianu, M.; Pascariu, P. Electrospun polymer-inorganic nanostructured materials and their applications. Polym. Rev. 2020, 60, 493-541. [CrossRef]

35. Garnett, E.C.; Cai, W.; Cha, J.J.; Mahmood, F.; Connor, S.T.; Christoforo, M.G.; Cui, Y.; McGehee, M.D.; Brongersma, M.L. Self-linited plasmonic welding of silver nanowire junctions. Nat. Mater. 2012, 11, 241-249. [CrossRef] [PubMed]

36. Parnian, K.; Alessandra, V.; Dalle, V.S.; Roberta, B. Photo-crosslinking of chitosan/poly(ethylene oxide) electrospun nanofibers. Carbohyd. Polym. 2019, 217, 144-151.

37. Cai, J.; Zhang, Q.; Lei, M.; He, J.; Liu, G. The use of solvent-soaking treatment to enhance the anisotropic mechanical properties of electrospun nanofiber membranes for water filtration. RSC Adv. 2016, 6, 66807-66813. [CrossRef]

38. Li, H.X.; Zhu, C.L.; Xue, J.J.; Ke, Q.F.; Xia, Y.N. Enhancing the mechanical properties of electrospun nanofiber mats through controllable welding at the cross points. Macromol. Rapid. Comm. 2017, 38, 1600723. [CrossRef]

39. Huang, L.W.; Manickam, S.S.; McCutcheon, J.R. Increasing strength of electrospun nanofiber membranes for water filtration using solvent vapor. J. Membrane. Sci. 2013, 436, 213-220. [CrossRef]

40. Ding, M.X. Isomeric Polyimide. Prog. Polym. Sci. 2007, 32, 623-668. [CrossRef]

41. Ding, Y.C.; Hou, H.Q.; Zhao, Y.; Zhu, Z.T.; Fong, H. Electrospun polyimide nanofibers and their application. Prog. Polym. Sci. 2016, 61, 67-103. [CrossRef]

42. Shen, Y.; Li, D.; Deng, B.; Liu, Q.; Liu, H.; Wu, T. Robust polyimide nano/microfibre aerogels welded by solvent-vapour for environmental applications. $R$ Soc. Open Sci. 2019, 6, 190596. [CrossRef] [PubMed]

43. Wenzel, R.N. Resistance of solid surfaces to wetting by water. Ind. Eng. Chem. 1936, 28, 988-994. [CrossRef]

44. Ghaffari, S.; Aliofkhazraei, M.; Darband, G.; Zakeri, A.; Ahmadi, E. Review of superoleophobic surfaces: Evaluation, fabrication methods, and industrial applications. Surf. Interfaces 2019, 17, 1000340. [CrossRef]

45. Xu, W.; Ding, Y.; Huang, R.; Zhu, Z.; Fong, H.; Hou, H. High-performance polyimide nanofibers reinforced polyimide nanocomposite films fabricated by co-electrospinning followed by hot-pressing. J. Appl. Polym. Sci. 2018, 135, 46849. [CrossRef]

46. Tripp, C.P.; Hair, M.L. Reaction of methylsilanols with hydrated silica surfaces: The hydrolysis of trichloro-, dichloro-, and monochloromethylsilanes and the effects of curing. Langmuir 1995, 11, 149-155. [CrossRef] 
47. Jung, H.; Ju, D.; Lee, W.; Zhang, X.; Kotek, R. Electrospun hydrophilic fumed silica/polyacrylonitrile nanofiber-based composite electrolyte membranes. Electrochim. Acta 2009, 54, 3630-3637. [CrossRef]

48. Leo, C.J.; Thakur, A.K.; Subba Rao, G.V.; Chowdari, B.V.R. Effect of glass-ceramic filler on properties of polyethylene oxide- $\mathrm{LiCF}_{3} \mathrm{SO}_{3}$ complex. J. Power Sources 2003, 115, 295-304. [CrossRef]

49. Kim, Y.J.; Ahn, C.H.; Lee, M.B.; Choi, M. Characteristics of electrospun $\mathrm{PVDF} / \mathrm{SiO}_{2}$ composite nanofiber membranes as polymer electrolyte. Mater. Chem. Phys. 2011, 127, 137-142. [CrossRef]

50. Gobi, N.; Vijayalakshmi, E.; Robert, B.; Srinivasan, N.R. Development of PAN nano fibrous filter hybridized by $\mathrm{SiO} 2$ nanoparticles electret for high efficiency air filtration. J. Polym. Mater. 2018, 35, 317-328. [CrossRef]

51. Li, X.; Wang, N.; Fan, G.; Yu, J.; Gao, J.; Sun, G.; Ding, B. Electreted polyetherimide-silica fibrous membranes for enhanced filtration of fine particles. J. Colloid Interface Sci. 2015, 439, 12-20. [CrossRef] [PubMed]

52. Wan, H.; Wang, N.; Yang, J.; Si, Y.; Chen, K.; Ding, B.; Sun, G.; EI-Newehy, M.; Al-Swyab, S.S.; Yu, J. Hierarchically structured polusulfone/titania fibrous membranes with enhanced air filtration performance. J. Colloid Interface Sci. 2014, 417, 18-26. [CrossRef] [PubMed]

Publisher's Note: MDPI stays neutral with regard to jurisdictional claims in published maps and institutional affiliations.

(C) 2020 by the authors. Licensee MDPI, Basel, Switzerland. This article is an open access article distributed under the terms and conditions of the Creative Commons Attribution (CC BY) license (http://creativecommons.org/licenses/by/4.0/). 